conciliar las dos afirmaciones suponiendo que la cantidad de dos mil incluye obras de todo tipo, mientras que "más de seiscientos" parece referirse sólo a comedias.

University of Tennessee.

Gerald E. WAde

\title{
"OÍ ... ASTROLOGÍA"
}

"Oí... astrología" (La verdad sospechosa, I, 3) es frase que se ha interpretado literalmente en todas las ediciones críticas de la comedia que he podido consultar ${ }^{1}$.

Después de un discurso en que el gracioso Tristán compara las mujeres de la corte con los astros del sistema de Ptolomeo, don García le pregunta,

¿Eres astrólogo?

Tristán responde:

Oí,

el tiempo que pretendía

en palacio, astrología ${ }^{2}$.

Alarcón, como Tristán, era pretendiente. Conocía la burocracia de funcionarios y privados que también se habían hecho astrólogos para poder augurar los gustos del monarca según la expresión de su cara. Y Alarcón les compadecía:

¡Fuerte caso, dura ley, que haya de ser el privado un astrólogo, colgado de los aspectos del rey! ${ }^{3}$

El, a su vez, podía repetir con el autor anónimo de la Epístola moral a Fabio:

Triste de aquel que vive destinado a esa antigua colonia de los vicios augur de los semblantes del privado ${ }^{4}$.

1 "Oír era asistir a clase...", Alfonso Reyes, Ruiz de Alarcón. Teatro, Madrid: Clás. Cast. vol. 37, 1948, pág. I6; "I studied astrology while I was seeking a government position", ARTHUR L. OWEN, La verdad sospechosa, Bostoll, 1928, pág. I 25 ; “... oír astrología équivaut à être étudiant en astrologie”, Ed. BARRY, La verdad sospechosa, París, I897, pág. 24; "Oír: "estudiar" ", P. Henríguez UReña y J. Bogliano, La verdad sospechosa, Buenos Aires, 1939, pág. 36; "Oír: Etudier sous un Maître une matière, suivre des cours de ...", G. Delpy y S. Denis, La verdad sospechosa, París, 1947, pág. 21.

2 BAAEE, XX, pág. 323a.

${ }^{3}$ BAAEE, XX, pág. Irb.

${ }^{4}$ The Oxford Book of Spanish Verse, Oxford, 1920, pág. 163. 
La metáfora era bastante común. Gracián la bajó de las estrellas al juego de naipes:

Mas los áulicos, como siempre están contemplando el rostro de su príncipe y brujuleándole los afectos...5

Tirso de Molina la dió cabida en uno de los episodios amorosos de los Cigarrales de Toledo:

... que reparando en él mis celos -astrólogos que conjeturan por las señales de la cara la ocasión que tienen para acrecentarse o disminuirse-.$- .6^{6}$

Es posible, pues, sugerir que la frase "oí . . . astrología" es otra construcción anfibológica, otro juego de palabras semejante a los muchos retruécanos y equívocos del discurso de Tristán. Así, con un juego menos obvio pero claro — según parece por los textos aducidos-, Tristán admite que había estudiado astrología en la corte, sólo que en el sentido figurado que por experiencia personal conocían muy bien los pretendientes como Tristán y como el mismo Alarcón.

The University of Southern California.

Joseph H. Silverman

\section{EL ORIGINAL INGLÉS DE UNA POESÍA DE ESPRONGEDA}

Es bien extraño que las publicaciones periódicas, a pesar de su reconocido valor dentro de la producción literaria del siglo xIx, no se hayan tenido en cuenta en relación con la obra de los emigrados españoles en Inglaterra durante el primer tercio de ese siglo. Es verdad que se ha prestado alguna atención a los periódicos que ellos mismos redactaron en español, pero olvidando, incomprensiblemente, la existencia de las publicaciones inglesas coetáneas.

Los emigrados españoles, como hemos indicado en otro lugar ${ }^{1}$, colaboraron en revistas inglesas; pero además de redactores fueron también lectores. Lo cual hay que decirlo, aunque tenga aire de perogrullada, porque a través de las laboriosas investigaciones dedicadas al estudio de las influencias inglesas en la obra de los emigrados se saca la impresión de que éstos no leyeron a lo sumo más que unos pocos libros, en una época precisamente en que el periódico literario había adquirido en Inglaterra nuevo y extraordinario desarrollo.

La despedida del patriota griego de la hija del apóstata, que figura

5 Baltasar Gracián, El Criticón, ed. Romera-Navarro, vol. II, pág. i67.

- Tirso de Molina, Cigarrales de Toledo, Madrid, Espasa-Calpe, I942, vol. I, pág. 89 .

1 HR, vol. XIX, I95I, págs. I2I-I42. 